\title{
Room temperature and low-temperature absorption and emission spectra of some polypyridylruthenium(II) 3.2.1 complexes
}

\author{
M.I. Silva*, H.D. Burrows, S.J. Formosinho, M.da G. Miguel \\ Departamento de Química, Universidade de Coimbra, 3004-535 Coimbra, Portugal \\ Received 31 August 2000; accepted 29 September 2000
}

\begin{abstract}
Electronic absorption and luminescence spectra are reported for a series of complexes of type $[\mathrm{Ru}(\mathrm{tpy})(\mathrm{L}-\mathrm{L})(\mathrm{py})]^{2+}$, where tpy and py are $2,2^{\prime}, 2^{\prime \prime}$-terpyridine and pyridine, and L-L represents the bidentate ligands bipyridyl, $4,4^{\prime}$-dimethylbipyridyl, 4 nitrobipyridyl, oxalate and acetylacetonate. The effect of solvent polarity and temperature on their spectral and light emission properties is studied. Energies are reported for the lowest-energy ${ }^{3} \mathrm{MLCT}^{*}$ excited state, and on the basis of these it is suggested that the complexes may make good triplet energy acceptors for use in organic and polymeric light emitting devices. (C) 2001 Elsevier Science B.V. All rights reserved.
\end{abstract}

Keywords: Polypyridine ruthenium(II) complexes; Luminescence; Triplet energy acceptors; Organic light emitting devices

\section{Introduction}

Although the spectra and photophysics of polypyridylruthenium(II) complexes have been studied for over 40 years [1], and have been extensively reviewed [2-4] they still attract wide interest. This is stimulated by the wide range of applications, varying from solar energy conversion [5], through oxygen sensors [6] to potential elements of organic or polymeric light emitting devices (LEDs) [7].

Since the earliest reports of efficient electroluminescence from organic [8] and polymeric [9,10] thin films, intense research activity has been devoted to the development of these systems, and the first commercial flat-panel displays involving organic LEDs are already available [11]. Electroluminescence involves

\footnotetext{
* Corresponding author. Tel.: +351-239-852080; fax: +351-239827703.

E-mail address: misilva@ci.uc.pt (M.I. Silva).
}

charge injection from appropriate electrodes, and the resulting electron-hole recombination produces singlet and triplet excited states roughly in the ratio $1: 3$ [12]. However, normally only the singlet states are efficient emitters, resulting in decreased luminescence efficiencies. Various energy transfer methods have been suggested to attempt to use the triplet energy in LEDs [13].

Light emission from polypyridylruthenium(II) complexes is known to come from the ${ }^{3} \mathrm{MLCT}^{*}$ excited state [2-4]. Because of the heavy atom effect, the spectral transition from the ground state to this excited state is less forbidden than most singlettriplet transitions. This will favour Förster-type [14] triplet energy transfer from excited states of conjugated polymers. The triplet energies of a series of conjugated polymers have recently been determined $[15,16]$. Matching the energies of these with the lowest triplet states of polypyridylruthenium(II) complexes may provide a method for highly efficient 


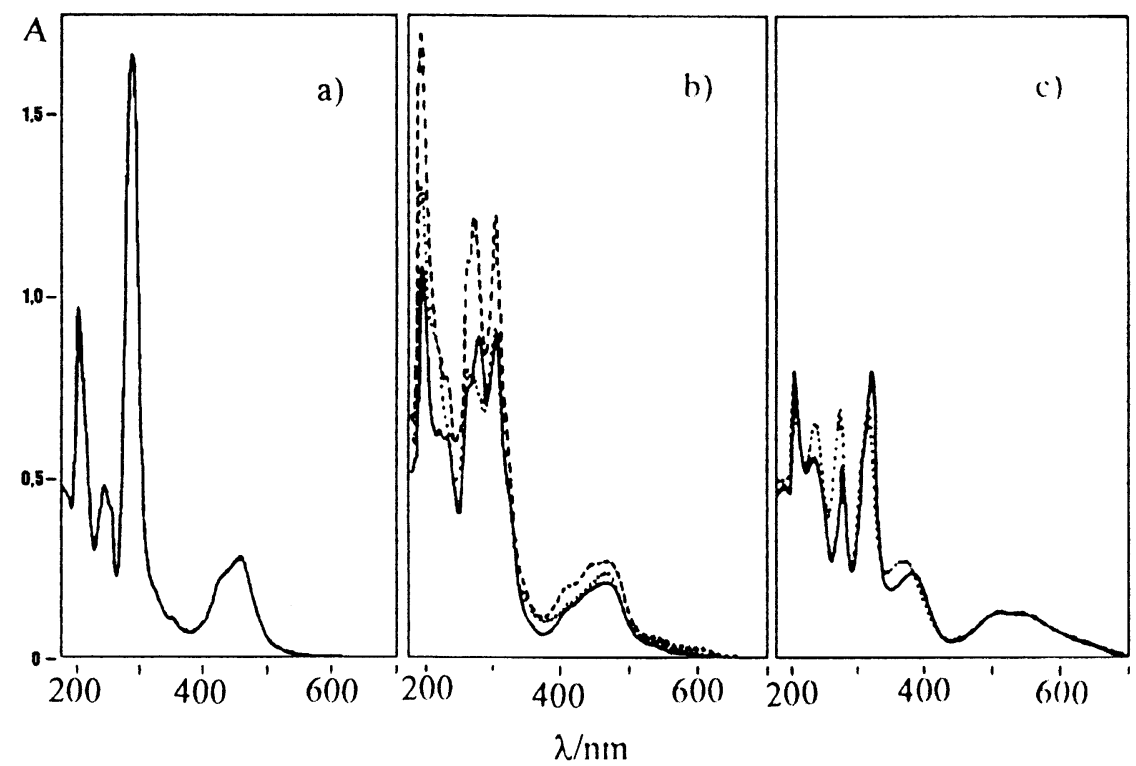

Fig. 1. Room temperature UV/visible absorption spectra of: (a) $\left[\mathrm{Ru}(\mathrm{bpy})_{3}\right]^{2+}$; (b) $\left.\left.[\mathrm{Ru}(\mathrm{tpy}) \mathrm{bpy})(\mathrm{py})\right]^{2+}(-) ;\left[\mathrm{Ru}_{(\mathrm{tpy})(\mathrm{Me}} \mathrm{bpy}\right)(\mathrm{py})\right]^{2+}(\cdots)$; $\left[\mathrm{Ru}(\text { tpy })\left(\mathrm{O}_{2} \mathrm{Nbpy}\right)(\mathrm{py})\right]^{2+}(--)$; and (c) $[\mathrm{Ru}($ tpy $)(\mathrm{ox})(\mathrm{py})](-) ;\left[\mathrm{Ru}(\right.$ tpy $)($ acac $)(\text { py) }]^{+}(\cdots)$. All solutions are at $2.5 \times 10^{-5} \mathrm{M}$ concentration in ethanol/methanol $(4: 1 \mathrm{v} / \mathrm{v})$.

energy transfer. For practical applications the complexes should be stable to photosubstitution, but be capable of bonding to polymeric or supramolecular systems.

We have synthesised a series of complexes of type $[\mathrm{Ru}(\mathrm{tpy})(\mathrm{L}-\mathrm{L})(\mathrm{py})]^{2+}$, where tpy and py are $2,2^{\prime}, 2^{\prime \prime}-$ terpyridine and pyridine, and $\mathrm{L}-\mathrm{L}$ represents the bidentate ligands bipyridyl (bpy), 4,4'-dimethylbipyridyl ( $\mathrm{Me}_{2}$ bpy), 4-nitrobipyridyl $\left(\mathrm{O}_{2} \mathrm{Nbpy}\right)$, oxalate (ox) and acetylacetonate (acac) [17]. For convenience we refer to these as 3.2.1 complexes, where the number refers to the denticity of the ligands. We report the electronic absorption and emission spectra of these compounds, with reference to their potential as energy acceptors in LEDs.

\section{Experimental}

The synthesis and characterisation of the ruthenium(II) complexes has been described in detail elsewhere [17]. UV-visible absorption spectra were measured on solutions in 1-cm quartz cuvettes using a Shimadzu UV-2100 spectrometer. Fluorescence emission and excitation spectra were obtained in $1-\mathrm{cm}$ quartz cuvettes on a Spex Fluorolog 111 spectrofluorimeter using a $90^{\circ}$ geometry. Appropriate filters were used to eliminate second-order bands. For lowtemperature measurements, samples were prepared in 3-4 mm quartz tubes immersed in liquid nitrogen.

\section{Results and discussion}

Absorption spectra were run on all samples in solution at room temperature (Fig. 1). In all cases, the lowest-energy absorption band corresponds to an intense $\mathrm{Ru}(\mathrm{d} \pi) \rightarrow($ tpy $) \pi^{*}$ MLCT transition. A slight red shift and sharpening of the peaks was observed on decreasing temperature [18]. Marked differences were observed between the spectra of the ox and acac complexes and those of the bpy derivatives. Further, differences were observed in the effect of solvent polarity on these bands in the acac and ox complexes compared with the bpy complexes, which we suggest are related to the electron donating character of these nonchromophoric ligands [17]. Luminescence in polypyridylruthenium(II) complexes results from phosphorescence from the lowest MLCT triplet state [2-4]. Luminescence spectra were run on the 3.2.1 

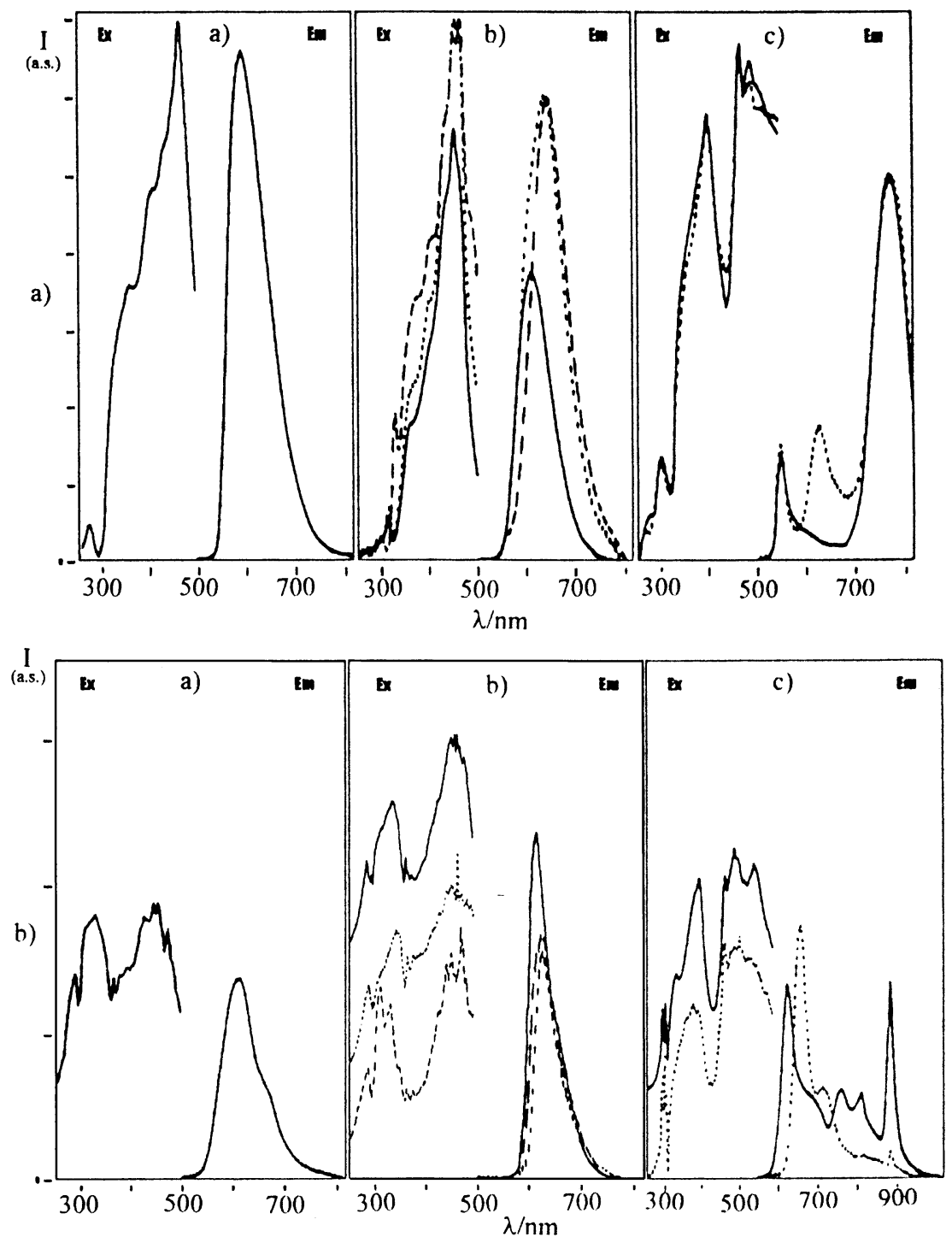

Fig. 2. (a) Room temperature excitation and emission spectra for ruthenium(II) 3.2.1 complexes; and (b) low-temperature excitation and emission spectra of the above complexes. The same symbols are used for the traces as in Fig. 1.

complexes at room temperature and $77 \mathrm{~K}$ (Fig. 2(a) and (b)). They all show weak phosphorescence at room temperature, but this increases dramatically on decreasing the temperature. Again, marked differences are observed in the spectra of the acac and ox derivatives compared with the other complexes. From the onset of the lowest-energy emission bands at $77 \mathrm{~K}$, energies were determined for the lowest ${ }^{3} \mathrm{MLCT}^{*}$ state, and are given in Table 1. It is seen that modifi- cation of the bidentate ligand allows considerable variation in the energy, which can then be matched with the lowest triplet state of the conjugated polymers. In addition, associated with the shifts in luminescence emission maxima there are corresponding changes in colour. This can possibly be used to modulate emission colour in LEDs.

In solution these complexes have been shown to undergo photosubstitution, largely by loss of pyridine 
Table 1

Energies of the lowest ${ }^{3} \mathrm{MLCT}^{*}$ states of ruthenium(II) 3.2.1 complexes

\begin{tabular}{lll}
\hline Complex & \multicolumn{2}{l}{ Triplet energy } \\
\cline { 2 - 3 } & $\mathrm{cm}^{-1}$ & $\mathrm{eV}$ \\
\hline$\left[\mathrm{Ru}(\text { bpy })_{3}\right]^{2+}$ & 19050 & 2.36 \\
{$[\mathrm{Ru}(\text { tpy })(\text { bpy })(\text { py })]^{2+}$} & 18690 & 2.32 \\
{$\left[\mathrm{Ru}(\text { tpy })\left(\mathrm{Me}_{2} \text { bpy }\right)(\text { py })\right]^{2+}$} & 18690 & 2.32 \\
{$\left[\mathrm{Ru}(\right.$ tpy $)\left(\mathrm{O}_{2} \mathrm{Nbpy}\right)(\text { py) }]^{2+}$} & 18690 & 2.32 \\
{$[\mathrm{Ru}($ tpy $)($ ox $)($ py $)]$} & 14285 & 1.77 \\
{$[\mathrm{Ru}(\text { tpy })(\text { acac })(\text { py })]^{+}$} & 14700 & 1.82 \\
\hline
\end{tabular}

[18]. This may assist in joining the 3.2.1 complexes to polymers such as polypyridine.

In conclusion, mixed polypyridine complexes of ruthenium(II) show considerable promise as energy acceptors for use with conjugated polymers. Future work will concentrate on the study of the energy transfer to these complexes in solution and films.

\section{Acknowledgements}

We are indebted to Professor T.J. Meyer and Drs S.A. Adeyemi and Z. Murtaza for the synthesis of these complexes. Financial assistance from PRAXIS XXI is gratefully acknowledged.

\section{References}

[1] J.P. Paris, W.W. Brandt, J. Am. Chem. Soc. 81 (1959) 5001.

[2] A. Juris, F. Barigelletti, S. Campagna, V. Balzani, P. Belser, A. von Zelewsky, Coord. Chem. Rev. 84 (1988) 85.

[3] T.J. Meyer, Acc. Chem. Res. 22 (1989) 163.

[4] K. Kalyanasundaram, Photochemistry of Polypyridine and Porphyrin Complexes, Academic Press, New York, 1992.

[5] B. O'Regan, M. Gratzel, Nature 353 (1991) 737.

[6] W. Xu, R.C. McDonough, B. Langsdorf, J.N. Demas, B.A. DeGraff, Anal. Chem. 66 (1994) 4133.

[7] T. Yamamoto, T. Maruyama, Z.-H. Zhou, T. Ito, T. Fukuda, Y. Yoneda, F. Begum, T. Ikeda, S. Sasaki, H. Takezoa, A. Fukuda, K. Kubota, J. Am. Chem. Soc. 116 (1994) 4832.

[8] C.W. Tang, S.A. VanSlyke, Appl. Phys. Lett. 51 (1987) 913.

[9] J.H. Burroughes, D.D.C. Bradley, A.R. Brown, R.N. Marks, K. Mackay, R.H. Friend, P.L. Burn, A.B. Holmes, Nature 347 (1990) 539.

[10] D. Braun, A.-J. Heeger, Appl. Phys. Lett. 58 (1991) 1982.

[11] A.H. Tullo, Chem. Eng. News 26 June (2000) 20.

[12] M.A. Baldo, D.F. O'Brien, M.E. Thompson, S.R. Forrest, Phys. Rev. B 60 (1999) 14422.

[13] M.A. Baldo, M.-E. Thompson, S.R. Forrest, Nature 403 (2000) 750.

[14] T. Förster, Discuss. Faraday Soc. 27 (1959) 7.

[15] A.P. Monkman, H.D. Burrows, L.J. Hartwell, L.E. Horsburgh, I. Hamblett, S. Navaratnam, Phys. Rev. Lett., submitted for publication.

[16] H.D. Burrows, M.da G. Miguel, A.P. Monkman, I. Hamblett, S. Navaratnam, J. Mol. Struct. 561-562 (2000) (in press).

[17] S.A. Adeyemi, H.D. Burrows, S.J. Formosinho, W. Jager, M.da G. Miguel, T.J. Meyer, Z. Murtaza, S. Schneider, M.I. Silva, in preparation.

[18] M.I. Silva, H.D. Burrows, M.da G. Miguel, S.J. Formosinho, in preparation. 